\title{
BARRIERS TO GOOD ORAL HEALTH FOR NURSING HOME RESIDENTS: A LITERATURE REVIEW
}

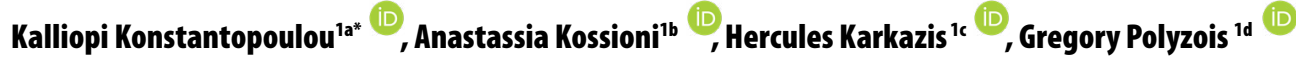 \\ 'Department of Prosthodontics, School of Dentistry, National and Kapodistrian University of Athens, Athens, Greece \\ aDDS, MSc; e-mail: kakonsta@dent.uoa.gr; ORCIDiD: https://orcid.org/0000-0002-4314-9222 \\ bDDS, MSc, Dr. Dent, Associate Professor; e-mail: akossion@dent.uoa.gr; ORCIDiD: https://orcid.org/0000-0003-0610-6984 \\ 'DDS, MSc,Dr. Dent; e-mail: hkarkaz@dent.uoa.gr; 0RCIDiD: https://orcid.org/0000-0002-9003-2852 \\ dDDS, Dr. Dent, MSCD; e-mail: grepolyz@dent.uoa.gr;ORCIDiD: https://orcid.org/0000-0003-0032-039X
}

\section{ABSTRACT}

d.) https://doi.org/10.25241/stomaeduj.2020.7(2).art.7

Background Oral health in older adults who live in nursing homes is generally poor, with high rates of mainly preventable oral conditions.

Objective The aim of this review was to present an overview of the barriers to good oral health for older nursing home residents.

Data sources Electronic databases were used (PubMed, Google Scholar, ScienceDirect). Reference lists from relevant studies and cited papers were also investigated.

Study selection The review included reports from national surveys and full papers of any study design, systematic reviews and guidelines published in peer-reviewed journals in English published until February 2019.

Data extraction The recorded barriers to good oral health were allocated to the main categories described in the socioecological model of health promotion.

Data synthesis The identified barriers to oral health of nursing home residents were allocated into intrapersonal, interpersonal, organizational and public health policy issues. The main intrapersonal barriers included the residents' physical and mental disease, resistance to care, poor oral health literacy and difficulties in accessing dental care. Interpersonal factors included inadequate knowledge and training of caregivers and health professionals on oral health and care for frail older people, as well as negative attitudes of caregivers and family members towards oral hygiene provision in nursing homes. Organizational factors included low priority of oral health in nursing homes, limitations in time and number of staff and limited collaboration with dental professionals. Ineffective oral health policies included lack of priority for oral health and unsupportive oral care systems.

\section{KEYWORDS}

Barriers; Oral Health; Oral Hygiene; Nursing Homes; Older Adults.

\section{INTRODUCTION}

Oral diseases are a major global public health problem affecting individuals, communities, and the society as a whole, as over 3,5 billion people face chronic and progressive oral diseases [1]. Older adults who reside in nursing homes are a particularly vulnerable part of the population with high rates of oral diseases.

Neglected oral health has severe consequences for the residents' general health and quality of life and has been associated with increased risk for aspiration pneumonia, diabetes mellitus, cardiovascular diseases and malnutrition [2-9].

Poor oral health has a considerable impact on the health care systems raising the health care costs [1013]. In addition, poor oral health may have a negative impact on social relationships due to altered speech, aesthetics, and oral comfort [13-16].

Oral care for nursing home residents does not often meet best practice standards [17] and several factors seem to act as barriers. The aim of this review was to offer an overview of the barriers to good oral health in older adults residing in nursing homes.

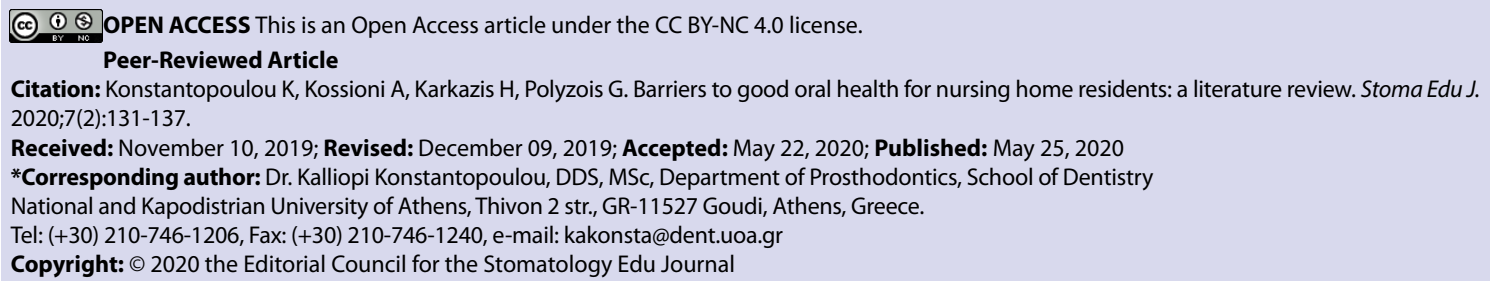




\section{MATERIALS AND METHODS}

A literature search in PubMed, Google Scholar, ScienceDirect and Scopus electronic databases was performed. The following keywords were used: (barriers) AND (oral health OR oral care) AND (nursing home residents $\mathrm{OR}$ dependent older adults). Moreover, reference lists from relevant studies and cited papers were also investigated. The titles and the abstracts of the retrieved articles were screened to decide whether full-text reading was required, and full texts were retrieved for the selected articles. The review included reports from national surveys and full papers of any study design, as well as guidelines, published in peer-reviewed journals in English. Articles published until February 2019 were included. According to the socioecological model of health promotion, poor oral health of residents in care units can be attributed to intrapersonal, interpersonal, organizational and public health policy issues. Therefore, the main barriers identified in the study were allocated to these specific categories.

\section{RESULTS}

The review has identified the following barriers to good oral health in nursing homes:

\subsection{Intrapersonal factors}

A number of barriers to oral health of nursing home residents are related to the residents themselves. Intrapersonal issues include physical illness, cognitive impairment and mobility problems leading to progressive self-care limitations and, subsequently, to difficulties in performing oral hygiene and accessing dental care [17-21]. Lower use of dental services may lead to the fast progression of oral diseases, delayed diagnosis and, as a result, to poor prognosis [22].

Studies in care units revealed poorer oral hygiene in functionally dependent older adults compared to residents with better self-care capacity $[23,24,25]$. Apart from the level of care dependency, increasing age, as well as communication and behavioral problems comprised additional barriers [8,26,27].

Polypharmacy is a major barrier to good oral health. In particular, cholinesterase inhibitors, atypical antipsychotics and antidepressants have significant oral side effects such as xerostomia or sialorrhea, stomatitis and dysgeusia. In addition, donepezil, galantamine, and risperidone interact with medications often administered bythedentist, suchaserythromycin,clarithromycin and ketoconazole [28-30]. Individual factors also include unhealthy dietary habits, and smoking, as well as the social determinants of health such as low educational level and limited income [31-33]. The presence of natural teeth and dental implants have also been characterized as barriers to good oral health, because of the complexity of oral hygiene procedures compared to dentures. However, poor retention and stability, and poor hygiene of the dentures may also negatively affect oral health causing denture-related stomatitis oral lesions $[17,27,34-36]$.

\subsection{Interpersonal factors}

Caregivers should examine the oral health status of the residents and provide or supervise the implementation of oral hygiene at least once a day $[37,38,39]$. However, the oral health of nursing homes residents does not receive the necessary attention and oral care neglect is more frequently observed compared to community dwelling elders [40]. The role of formal caregivers in nursing homes is crucial for the everyday general and oral care of frail and functionally dependent residents. Inadequate theoretical and practical education of nursing home staff in oral health and care has been well documented [34,41-45].

Caregivers have poor knowledge and skills on oral hygiene advice and assistance [18,25]. Moreover, they do not have adequate knowledge in detecting common oral pathologies such as caries, periodontitis and stomatitis, and in the correct procedures for oral hygiene implementation $[42,46]$. Furthermore, they do not use the available educational resources on oral care. Some caregivers, also, do not understand the need for certain oral care activities and they think that the implementation of oral hygiene is based on their preexisting knowledge [19]. According to the caregivers' perceptions, a major barrier to oral hygiene provision is the residents' negative responsive behaviors and resistance (i.e. not opening their mouth, biting the toothbrush or the caregivers' hands, shouting, etc.). However, the caregivers' close relationships with the residents and a personcentered approach can play a key role in preventing or managing responsive behaviors of older adults with dementia. Nevertheless, care providers are deprived of proper education in overcoming care resistant behaviors and are unaware that aggressive behaviors of residents with dementia may express pain, fear or resentment [8,47-51]. Furthermore, caregivers believe that the residents experience oral hygiene as intimate or painful. The poor cooperation among caregivers may also cause communication problems [8,21,35,52-54]. Caregivers also consider oral care of low priority and believe that it is not included in their job responsibilities $[19,20,43,55,56]$. Oral care and removal of dentures is considered as an unpleasant and repulsive process, mainly due to oral halitosis and bacteria prevalence $[20,25,34,57]$. For some caregivers, oral care is considered as more unpleasant compared to general care (feeding, washing or changing diapers) and they feel exhausted after applying oral hygiene [44,58]. Other reported barriers include the lack of empathy, laziness and belief that residents can manage oral care themselves $[44,59]$. Lack of professional support is also associated with the insecurity of the dentists to provide oral care in medically compromised older people, particularly 
in domiciliary settings $[39,60,67]$, as well as the limited knowledge of physicians to integrate oral health into the general medical assessment [39]. Interpersonal factors also include barriers related to the residents' family members. Family members' oral health literacy is often inadequate $[20,61,62]$ and there is lack of understanding of the need to improve the quality of oral health and care [63]. They often do not support the formal caregivers in the provision of oral hygiene to the older family members $[60,61,63]$, and do not purchase oral care supplies for their relatives, due to their high cost or perceived low priority of oral care [8].

\subsection{Organizational factors}

Barriers to oral health associated with the organization of nursing home services include lack of oral care routines and instructions, and unclear rationale for implementing oral care recommendations $[20,21,41,54,64]$. The lack of a nursing team leader and of proper supervision, monitoring, enforcing and rewarding the caregivers' oral hygiene practices are important determinants of proper oral hygiene implementation $[8,21,65]$. On theotherhand,common findingsinthecare unitsarethelownumbers of nursing staff and the limited time assigned to oral hygiene provision $[19,20,25,34,35,52,53,62,65]$. Caregivers face high workloads and are frequently interrupted while providing care to the residents $[46,63,65]$. Therefore, the number of residents in long-term care institutions seemed to have a negative impact on oral hygiene practices [26]. Despite the nursing staff's willingness to improve the oral health of the residents, their increased workload posed significant difficulties in integrating oral care into the daily care routine $[17,37]$. The above factors may lead to the low caregivers' satisfaction with their work, burn-out and, consequently, to a low quality of care $[8,46,63,65]$. Moreover, the caregivers' rush to provide timely daily care may trigger the residents' aggressive behavior, especially those with dementia [47,51]. Additional barriers are the lack of financial resources to buy the necessary oral hygiene supplies [17,18,34,35], the lack of dentures' labelling [34] and the absence of a dental chair at the nursing homes' premises [66]. It should also be noticed that a significant barrier to good oral health in nursing homes is the lack of integration of oral health assessment into the general health examination provided by the unit's physician and the limited collaboration with a dental professional who will regularly assess the oral health of the residents and manage any urgent and routine oral problems [39].

\subsection{Public policy issues}

The lack of appropriate oral health policies is well documented. Public dental care coverage is limited in most countries, socio-economic inequalities reduce access to dental care and oral health literacy of the public is poor $[39,67]$. Finally, there is poor availability of domiciliary dental services and lack of appropriate legislation to support oral care for the older adults living in care units or being confined at home $[37,39,67]$.

\section{DISCUSSION}

This review has identified several barriers to good oral health in nursing home residents related to intrapersonal, interpersonal, organizational and public policy issues. The caregivers' lack of oral health education and increased workload, along with limited access to dental care for the residents were the dominant barriers.

Older residents face a rapid oral health deterioration due to several risk factors which include general health factors, oral conditions and lack of social and institutional support [68]. Poor oral hygiene implementation has been associated with the caregivers' inadequate knowledge, training and skills for oral hygiene assessment and provision, the limitations in the number of staff and their time availability for oral care, the poor communication with the residents, the residents' low interest or even their resistance to oral care $[8,17,19,21,25,34,35,52,53,69]$. The main barriers regarding the provision of dental treatment are the limited collaboration of nursing homes with dental practitioners, the lack of suitable facilities for treatment on site, the difficulties in the transportation of the residents to the dental offices, their refusal to receive dental care, the limited preparedness of dentists to manage frail and caredependent older people, the poor oral health policies including the lack of oral health integration into public health care coverage, and the limited provision of domiciliary care $[39,69]$.

The study of Hilton, et al. (2016) describes findings from a focus group of nurses and residential care workers identifying large discrepancies between the existing recommendations for oral care in nursing homes and their actual implementation [17]. The results revealed the caregivers' substantial gaps in oral care training, the limited access to appropriate equipment and professional support, the residents resisting behaviors to oral hygiene, the inadequate staffing and the staff's negative attitudes towards the provision of oral care [17]. Difficulties in oral care provision regarding dysphagia, dementia and poor fit of the dentures are common and it is of utmost importance to be addressed [17]. Interestingly, the members of the focus group suggested that lack of time should not be a barrier in converting the daily implementation of oral health practices in residential care settings to a priority [17]. This study highlights the need for the implementation of appropriate oral health education programmes for nursing homes' staffand of the necessary organizational interventions based on the existing recommendations by the European College of Gerodontology (ECG) and the European Geriatric Medicine Society (EUGMS) [39]. These recommendations include a compulsory oral health assessment together with the medical entry 
assessment, daily oral hygiene provision, oral health education for the caregivers, availability of oral care products, accessibility to emergency and routine oral care, regular oral screenings and a healthy diet [39]. However, there is lack of robust evidence on the prevalence, predictors and consequences of the various barriers and facilitators to oral health in nursing homes $[8,69]$. Because of the specific characteristics of the nursing home population with high levels of cognitive impairment, the implementation and testing of effective oral hygiene protocols raise significant difficulties and demand adapted procedures [70]. Based on systematic reviews' findings, most of the related studies generally have a low methodological quality and a high risk of bias especially in terms of sample size, research tools and assessment of confounding factors, while most studies were mainly conducted in high-income countries and, therefore, generalization of the findings is limited $[8,68]$. Future research should include studies on the existing and novel oral health practices in nursing homes to thoroughly determine the barriers to the residents' oral care [17]. The development of appropriate strategies to prevent and manage the residents' negative attitudes and behaviors and enhance the caregivers' oral care knowledge and attitudes is also crucial $[8,39,71]$. Moreover, appropriate legislation and policies for oral health prevention and promotion in institutional settings according to the recommendations of the European College of Gerodontology (ECG) and the European Geriatric Medicine Society (EUGMS) should be implemented [39].

\section{CONCLUSIONS}

Several barriers in oral health prevention and promotion for nursing home residents have been reportedatanindividual,interpersonal,organizational and public policy level. A more rigorous research and a thorough understanding of these barriers will lead to the design and implementation of effective oral health promotion strategies for the vulnerable older population.

\section{CONFLICT OF INTEREST}

We declare no conflict of interest of any kind.

\section{AUTHORS CONTRIBUTIONS}

KK: protocol, data gathering, data analysis, authoring the draft. AK: concept, protocol, critically revising the manuscript. HK, GP: critically revising the manuscript.

\section{REFERENCES}

1. Watt RG, Daly B, Allison $P$, et al. Ending the neglect of global oral health: time for radical action. Lancet. 2019;394(10194):261272. doi:10.1016/S0140-6736(19)31133-X.

[CrossRef] [PubMed] Google Scholar Scopus

2.Dey AN. Characteristics of elderly nursing home residents: data from the 1995 National Nursing Home Survey. Adv Data. 1997;(289):1-8.

[Full text links] [PubMed] [Google Scholar] Scopus

3. Fitzpatrick J. Oral health care needs of dependent older people: responsibilities of nurses and care staff. J Adv Nurs. 2000;32(6):1325-1332. doi:10.1046/j.1365-2648.2000.01631.x. [CrossRef] [PubMed] Google Scholar Scopus

4. Janssens B, Vanobbergen J, Petrovic M, et al. The oral health condition and treatment needs assessment of nursing home residents in Flanders (Belgium). Community Dent Health. 2017;34(3):143-151. doi:10.1922/CDH_4086Janssens09. [Full text links] [PubMed] Google Scholar

5. Kiyak HA, Grayston MN, Crinean CL. Oral health problems and needs of nursing home residents. Community Dent Ora Epidemiol. 1993;21(1):49-52. doi:10.1111/j.1600-0528.1993. tb00719.x.

[CrossRef] [PubMed] Google Scholar Scopus

6. Manderson RD, Ettinger RL. Dental status of the institutionalized elderly population of Edinburgh. Community Dent Oral Epidemiol. 1975;3(3):100-107. doi:10.1111/j.1600-0528.1975.tb00289.x.

[CrossRef] [PubMed] Google Scholar Scopus

7. Weening-Verbree L, Huisman-de Waal G, van Dusseldorp L, et al. Oral health care in older people in long term care facilities: a systematic review of implementation strategies. Int J Nurs Stud. 2013;50(4):569-582. doi:10.1016/j.ijnurstu.2012.12.004.

[CrossRef] [PubMed] Google Scholar Scopus

8. Hoben M, Clarke A, Huynh KT, et al. Barriers and facilitators in providing oral care to nursing home residents, from the perspective of care aides: a systematic review and meta-analysis. Int J Nurs Stud. 2017;73:34-51. doi:10.1016/j.ijnurstu.2017.05.003. [CrossRef] [PubMed] Google Scholar Scopus

9. Awano S, Ansai T, Takata Y, et al. Oral health and mortality risk from pneumonia in the elderly. J Dent Res. 2008;87(4):334-339. doi:10.1177/154405910808700418.

[CrossRef] PubMed Google Scholar Scopus

10. Azarpazhooh A, Tenenbaum HC. Separating fact from fiction: use of high-level evidence from research syntheses to identify diseases and disorders associated with periodontal disease. J Can Dent Assoc. 2012;78:c25.

[Full text links] [CrossRef] [PubMed] Google Scholar Scopus 11. Emami E, de Souza RF, Kabawat M, Feine JS. The impact of edentulism on oral and general health. Int J Dent.

2013;2013:498305. doi:10.1155/2013/498305.

[CrossRef] [Free PMC Article] Google Scholar Scopus

12. Frenkel H, Matthews DC, Nitschke I. Prevention of oral diseases for a dependent population. In: MacEntee MI, Müller F, Wyatt C, editors. Oral Healthcare and the Frail Elder-A clinical perspective. First ed. Ames, IA 50014-8300, USA: Wiley-Blackwell; 2011:187-209.

[CrossRef] Google Scholar

13. Haumschild MS, Haumschild RJ. The importance of oral health in long-term care. J Am Med Dir Assoc. 2009;10(9):667-671. doi:10.1016/j.jamda.2009.01.002.

[CrossRef] [PubMed] Google Scholar Scopus

14. Petersen PE, Yamamoto T. Improving the oral health of older people: the approach of the WHO Global Oral Health Programme. Community Dent Oral Epidemiol. 2005;33(2):81-92. doi:10.1111/ j.1600-0528.2004.00219.x.

[CrossRef] [PubMed] Google Scholar Scopus

15. Niesten D, van Mourik K, van der Sanden W. The impact of having natural teeth on the QoL of frail dentulous older people. A qualitative study. BMC Public Health. 2012;12:839. doi:10.1186/1471-2458-12-839.

[Full test links] [Free PMC Article] [PubMed] Google Scholar Scopus

16. Rouxel P, Tsakos G, Chandola T, Watt RG. Oral health-a neglected aspect of subjective well-being in later life. J Gerontol B Psychol Sci Soc Sci. 2018;73(3):382-386. doi:10.1093/geronb/ gbw024.

[Full text links] [PubMed] Google Scholar Scopus 
17. Hilton S, Sheppard JJ, Hemsley B. Feasibility of implementing oral health guidelines in residential care settings: views of nursing staff and residential care workers. Appl Nurs Res. 2016:30:194-203. doi:10.1016/j.apnr.2015.10.005.

[CrossRef] [PubMed] Google Scholar Scopus 18. Paulsson G, Söderfeldt B, Nederfors T, Fridlund B. Nursing personnel's views on oral health from a health promotion perspective: a grounded theory analysis. Acta Odontol Scand. 2002;60(1):42-49. doi:10.1080/000163502753471998.

[CrossRef] Google Scholar Scopus

19. McKelvey VA, Thomson WM, Ayers KM. A qualitative study of oral health knowledge and attitudes among staff caring for older people in Dunedin long-term care facilities. N Z Dent J. 2003;99(4):98-103.

[PubMed] Google Scholar

20. McNally ME, Martin-Misener R, Wyatt CC, et al. Action planning for daily mouth care in long-term care: the brushing up on mouth care project. Nurs Res Pract. 2012;2012:368356. doi:10.1155/2012/368356

[Full test links] [CrossRef] [Free PMC Article] Google Scholar 21. De Visschere $L$, de Baat $C$, De Meyer $L$, et al. The integration of oral health care into day-to-day care in nursing homes: a qualitative study. Gerodontology. 2015;32(2):115-122. doi:10.1111/ger.12062.

CrossRef] [PubMed] Google Scholar Scopus

22. Peres MA, Macpherson LMD, Weyant RJ, et al. Oral diseases: a global public health challenge [published correction appears in Lancet. 2019 Sep 21;394(10203):1010]. Lancet 2019;394(10194):249-260. doi:10.1016/S0140-6736(19)31146-8. [CrossRef] [PubMed] Google Scholar

23. Zuluaga DJ, Ferreira J, Montoya JA, Willumsen T. Oral health in institutionalized elderly people in Oslo, Norway and its relationship with dependence and cognitive impairment. Gerodontology. 2012;29(2):e420-e426. doi:10.1111/j.17412358.2011.00490.x.

[Full text links] [CrossRef] [PubMed] Google Scholar Scopus 24. Philip P, Rogers C, Kruger E, Tennant M. Oral hygiene care status of elderly with dementia and in residential aged care facilities. Gerodontology. 2012;29(2):e306-e311.

doi:10.1111/j.1741-2358.2011.00472x.

[Full text links] [CrossRef] [PubMed] Google Scholar Scopus 25. Willumsen T, Karlsen L, Naess R, Bjørntvedt S. Are the barriers to good oral hygiene in nursing homes within the nurses or the patients? Gerodontology. 2012;29(2):e748-e755. doi:10.1111/ .1741-2358.2011.00554.x.

[Full text links] [CrossRef] [PubMed] Google Scholar

26. Vanobbergen JN, De Visschere LM. Factors contributing to the variation in oral hygiene practices and facilities in longterm care institutions for the elderly. Community Dent Health. 2005;22(4):260-265.

[Full text links] [PubMed] Google Scholar Scopus 27. Tham $\mathrm{R}$, Hardy $\mathrm{S}$. Oral healthcare issues in rural residential aged care services in Victoria, Australia. Gerodontology. 2013;30(2):126-132. doi:10.1111/j.1741-2358.2012.00652.x. [CrossRef] [PubMed] Google Scholar Scopus

28. Fiske J, Frenkel H, Griffiths J, Jones V; British Society of Gerodontology; British Society for Disability and Oral Health. Guidelines for the development of local standards of oral health care for people with dementia. Gerodontology. 2006;23 Suppl .5-32 doi:10.1111/j.1741-2358.2006.00140x. [CrossRef] [PubMed] Google Scholar

29. Friedlander AH, Norman DC, Mahler ME, et al. Alzheimer's disease: psychopathology, medical management and dental implications. J Am Dent Assoc. 2006;137(9):1240-1251. doi:10.14219/jada.archive.2006.0381

CrossRef] Google Scholar [PubMed] Scopus

30. Turner LN, Balasubramaniam R, Hersh EV, Stoopler ET. Drug therapy in Alzheimer disease: an update for the oral health care provider. Oral Surg Oral Med Oral Pathol Oral Radiol Endod. 2008;106(4):467-476. doi:10.1016/j.tripleo.2008.06.009. [CrossRef] [PubMed] Google Scholar Scopus 31. Borreani E, Wright D, Scambler S, Gallagher JE. Minimising barriers to dental care in older people. BMC Oral Health. 2008;8:7. Published 2008 Mar 26, doi:10.1186/1472-6831-8-7. [Full text links] [Free PMC Article] [PubMed] Google Scholar Scopus

32. Ornstein KA, DeCherrie L, Gluzman R, et al. Significant unmet oral health needs of homebound elderly adults. J Am Geriatr Soc. 2015;63(1):151-157. doi:10.1111/jgs.13181

[Full text links] [CrossRef] [Free PMC Article] Google Scholar Scopus

33. Strayer MS. Perceived barriers to oral health care among the homebound. Spec Care Dentist. 1995;15(3):113-118.

doi:10.1111/j.1754-4505.1995.tb00492x.

[CrossRef] [PubMed] Google Scholar Scopus
34. Dharamsi S, Jivani K, Dean C, Wyatt C. Oral care for frail elders: knowledge, attitudes, and practices of long-term care staff. J Dent Educ. 2009;73(5):581-588. [Full text links] [CrossRef] [PubMed] Google Scholar

35. Paley GA, Slack-Smith LM, O'Grady MJ. Aged care staff perspectives on oral care for residents: Western Australia. Gerodontology. 2004;21(3):146-154. doi:10.1111/j.1741-

2358.2004.00020.x.

[CrossRef] [PubMed] Google Scholar Scopus

36. Porter J, Ntouva A, Read A, et al. The impact of oral health on the quality of life of nursing home residents. Health Qual Life Outcomes. 2015:13:102 doi:10.1186/s12955-015-0300-y. [Full text links] [CrossRef] [PubMed] Google Scholar Scopus 37. De Visschere LM, van der Putten GJ, Vanobbergen JN, Schols JM, de Baat C; Dutch Association of Nursing Home Physicians. An oral health care guideline for institutionalized older people. Gerodontology. 2011;28(4):307-310. doi:10.1111/j.1741-2358. 2010.00406.x

[CrossRef] [PubMed] Google Scholar Scopus

38. O'Connor LJ. Oral health care. In: Boltz M, Capezuti E, Fulme T, Zwiker D, editors. Evidence-based geriatric nursing protocols for best practice. Fifth ed. New York, NY10036, USA: Springer Publishing Company; 2016:103-110.

[Full text links]

39. Kossioni AE, Hajto-Bryk J, Maggi S, et al. An expert opinion from the European College of Gerodontology and the European Geriatric Medicine Society: European policy recommendations on oral health in older adults. J Am Geriatr Soc. 2018;66(3):609-

613. doi:10.1111/jgs.15191.

[Full text links] [CrossRef] [PubMed] Google Scholar Scopus 40. Raja BK, Radha G, Rekha R, Pallavi SK. Oral health status of institutionalized elder's. Int J Oral Health Med Res. 2015;2(1):86-91. [Full text links] Google Scholar

41. Frenkel H, Harvey I, Needs K. Oral health care education and its effect on caregivers' knowledge and attitudes: a randomised controlled trial. Community Dent Oral Epidemiol. 2002:30(2):91100. doi:10.1034/j.1600-0528.2002.300202.x. [CrossRef] [PubMed] Google Scholar Scopus

42. Janssens B, De Visschere L, van der Putten GJ, et al. Effect of an oral healthcare protocol in nursing homes on care staffs knowledge and attitude towards oral health care: a clusterrandomised controlled trial. Gerodontology. 2016;33(2):275-286. doi:10.1111/ger.12164.

[CrossRef] [PubMed] Google Scholar Scopus

43. Lindqvist L, Seleskog B, Wårdh I, von Bültzingslöwen I. Oral care perspectives of professionals in nursing homes for the elderly. Int J Dent Hyg. 2013;11 (4):298-305. doi:10.1111/idh.12016. [CrossRef] [PubMed] Google Scholar Scopus

44. Sloane PD, Zimmerman S, Chen X, et al. Effect of a person-centered mouth care intervention on care processes and outcomes in three nursing homes. J Am Geriatr Soc. 2013;61(7):1158-1163. doi:10.1111/jgs.12317.

[CrossRef] [PubMed] Google Scholar Scopus

45. Wårdh $\mathrm{I}$, Jonsson $\mathrm{M}$, Wikström $\mathrm{M}$. Attitudes to and knowledge about oral health care among nursing home personnel--an area in need of improvement. Gerodontology. 2012;29(2):e787-e792. doi:10.1111/j.1741-2358.2011.00562.x.

[Full text links] [CrossRef] [PubMed] Google Scholar Scopus 46. De Visschere L, de Baat C, De Meyer L, et al. The integration of oral health care into day-to-day care in nursing homes: a qualitative study. Gerodontology. 2015;32(2):115-122. doi:10.1111/ger.12062.

[CrossRef] [PubMed] Google Scholar Scopus

47. Eggenberger E, Heimerl K, Bennett MI. Communication skills training in dementia care: a systematic review of effectiveness, training content, and didactic methods in different care settings Int Psychogeriatr. 2013:25(3):345-358 doi:10.1017/ S1041610212001664.

[Full text links] [PubMed] [Google Scholar] Scopus 48. Kuske B, Hanns S, Luck T, et al. Nursing home staff training in dementia care: a systematic review of evaluated programs. Int Psychogeriatr. 2007;19(5):818-841. doi:10.1017/ S1041610206004352.

[Full text links] [CrossRef] [PubMed] Google Scholar Scopus 49. Scott A, Ryan A, James I, Mitchell EA. Perceptions and implications of violence from care home residents with dementia: a review and commentary. Int J Older People Nurs. 2011;6(2):110-122. doi:10.1111/j.1748-3743.2010.00226.x [CrossRef] [PubMed] Google Scholar Scopus

50. Spector A, Orrell M, Goyder J. A systematic review of staff training interventions to reduce the behavioural and psychological symptoms of dementia. Ageing Res Rev. 2013;12(1):354-364. doi:10.1016/j.arr.2012.06.005.

[Full text Inks] [CrossRef] [PubMed] Google Scholar Scopus 51. Spenceley S, Witcher CS, Hagen B, et al. Sources of 
moral distress for nursing staff providing care to residents with dementia. Dementia (London). 2017;16(7):815-834. doi:10.1177/1471301215618108.

[Full text links] [CrossRef] [PubMed]Google Scholar Scopus 52. Jablonski RA, Munro CL, Grap MJ, et al. Mouth care in nursing homes: knowledge, beliefs, and practices of nursing assistants. Geriatr Nurs. 2009;30(2):99-107. doi:10.1016/j. gerinurse.2008.06.010.

[Free PMC Article] [CrossRef] [PubMed] Google Scholar Scopus

53. Junges R, Portella FF, Hugo FN, et al. Caregivers' attitudes regarding oral health in a long-term care institution in Brazil. Gerodontology. 2014;31(3):178-183. doi:10.1111/ger.12019. [Full text links] [PubMed] [CrossRef] Google Scholar Scopus 54. Wårdh IM, Wikström MB. Long-term effects of using oral care aides at a nursing home for elderly dependent residents--a pilot study. Spec Care Dentist. 2014;34(2):64-69. doi:10.1111/scd.12009. [CrossRef] Google Scholar Scopus

55. Chalmers JM, Levy SM, Buckwalter KC, et al. Factors influencing nurses' aides' provision of oral care for nursing facility residents. Spec Care Dentist. 1996;16(2):71-79. doi:10.1111/j.1754-4505.1996.tb00837x.

[CrossRef] Google Scholar Scopus

56. Fiske J, Lloyd HA. Dental needs of residents and carers in elderly peoples' homes and carers' attitudes to oral health. Eur J Prosthodont Restor Dent 1992;1(2):91-95.

[CrossRef] Google Scholar Scopus

57. Reed R, Broder HL, Jenkins $\mathrm{G}$, et al. Oral health promotion among older persons and their care providers in a nursing home facility. Gerodontology. 2006;23(2):73-78. doi:10.1111/j.17412358.2006.00119.x.

[CrossRef] [PubMed] Google Scholar Scopus

58. Sumi Y, Nakamura Y, Nagaosa S, et al. Attitudes to oral care among caregivers in Japanese nursing homes. Gerodontology. 2001;18(1):2-6. doi:10.1111/j.1741-2358.2001.00002.x.

[CrossRef] [PubMed] Google Scholar Scopus

59. Wårdh I, Andersson L, Sörensen S. Staff attitudes to oral health care. A comparative study of registered nurses, nursing assistants and home care aides. Gerodontology. 1997;14(1):28-32. doi:10.1111/j.1741-2358.1997.00028.x.

[Full text links] [CrossRef] [PubMed] Google Scholar Scopus 60. Gallagher JE, Fiske J. Special care dentistry: a professional challenge. Br Dent J. 2007:202(10):619-629. doi:10.1038/ bdj.2007.426.

[Full text links] [PubMed] Google Scholar

61. Fricker A, Lewis A. Better oral health in residential care: final report. Central Northern Adelaide Health Service, South Australian Dental Service, Adelaide. [Internet] 2009. [cited 2019 October 10].

Available from: https://www.sahealth.sa.gov.au/wps/wcm/con nect/32902a8043506b6a91bef32835153af6/SADS-BOHP-FinReport-Nov-09.pdf

[Full text links]
62. Tan $\mathrm{H}$, Spencer AJ, Jones $\mathrm{K}$, Jeffery L. Impacts of the better oral health in residential care project on oral health care and oral health in residential aged care. Australian Research Centre for Population Oral Health, University of Adelaide, Adelaide; 2009.

[Full text links]

63. Wårdh I, Hallberg LR, Berggren U, et al. Oral health education for nursing personnel; experiences among specially trained oral care aides: one-year follow-up interviews with oral care aides at a nursing facility. Scand J Caring Sci. 2003;17(3):250-256. doi:10.1046/j.1471-6712.2003.00214.x

[Full text links] [CrossRef] [PubMed] Google Scholar Scopus 64. de Mello AL, Padilha DM. Oral health care in private and small long-term care facilities: a qualitative study. Gerodontology. 2009;26(1):53-57. doi:10.1111/j.1741-2358.2008.00238.x. [CrossRef] [PubMed] Google Scholar Scopus

65. Chami K, Debout C, Gavazzi G, et al. Reluctance of caregivers to perform oral care in long-stay elderly patients: the three interlocking gears grounded theory of the impediments. J Am Med Dir Assoc. 2012;13(1):e1-e4. doi:10.1016/j.jamda.2011.06.007. [CrossRef] [PubMed] Google Scholar Scopus

66. Gopalakrishnan A, Kahu E, Jones L, Brunton P. Access and barriers to oral health care for dependent elderly people living in rest homes. Gerodontology. 2019;36(2):149-155. doi:10.1111/ ger.12392.

[CrossRef] [PubMed] Google Scholar Scopus

67. Kossioni AE. Is Europe prepared to meet the oral health needs of older people? Gerodontology. 2012;29(2):e1230-e1240. doi:10.1111/j.1741-2358.2010.00445.x

[Full text links] [CrossRef] [PubMed] Google Scholar

68. Marchini L, Hartshorn JE, Cowen $\mathrm{H}$, et al. A Teaching tool for establishing risk of oral health deterioration in elderly patients: development, implementation, and evaluation at a U.S. Dental School. J Dent Educ. 2017;81(11):1283-1290. doi:10.21815/ JDE.017.086.

[Full text links] [CrossRef] [PubMed] Google Scholar Scopus 69. Göstemeyer G, Baker SR, Schwendicke F. Barriers and facilitators for provision of oral health care in dependent older people: a systematic review. Clin Oral Investig. 2019;23(3):979993. doi:10.1007/s00784-019-02812-4.

[CrossRef] PubMed Google Scholar Scopus

70. Marchini L, Recker E, Hartshorn J, et al. lowa nursing facility oral hygiene (INFOH) intervention: a clinical and microbiological pilot randomised trial. Spec Care Dentist. 2018:38(6):345-355. doi: $10.1111 /$ scd. 12327.

[Free PMC Article] [CrossRef] [PubMed] Google Scholar

71. Kossioni AE. Recommended action plans for oral health in older Europeans. Stoma Edu J. 2018;5(1):6-7. [Full Text Links] Google Scholar

\section{Kalliopi KONSTANTOPOULOU} DDS, MSC

Department of Prosthodontics School of Dentistry National and Kapodistrian University of Athens Athens, Greece

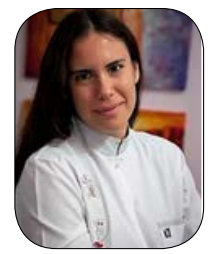

Kalliopi Konstantopoulou graduated from the School of Dentistry of the National and Kapodistrian University of Athens, Greece in 2016. In 2019, she obtained her master's degree in Health Promotion and Education from the Medical School of the National and Kapodistrian University of Athens and became a postgraduate student at the Department of Prosthodontics (School of Dentistry, National and Kapodistrian University of Athens, Athens, Greece). 


\section{Orestions}

1. According to the socioecological model in health promotion, which of the following factors may deteriorate oral health of older nursing home residents?

$\square$ a. Factors associated with the residents themselves;

ab. Interpersonal factors;

ac. Organizational and public policy issues;

$\square d$. All of the aforementioned.

\section{A common side effect of polypharmacy is?}

Da. Gingivitis;

ab. Periodontitis;

ac. Xerostomia;

$\square$ d. Teeth discoloration.

\section{According to caregivers' perceptions, which is the major barrier to oral care provision?}

a. Lack of oral care supplies;

ab. Residents' responsive behaviors and resistance;

ac. Lack of support by residents' family members;

ad. Poor cooperation among caregivers.

\section{The lack of appropriate oral health policies is related to?}

a. Poor availability of domiciliary dental services;

ab. Lack of oral health integration into public health care coverage;

ac. Poor oral health literacy of the public;

$\square \mathrm{d}$. All of the aforementioned.

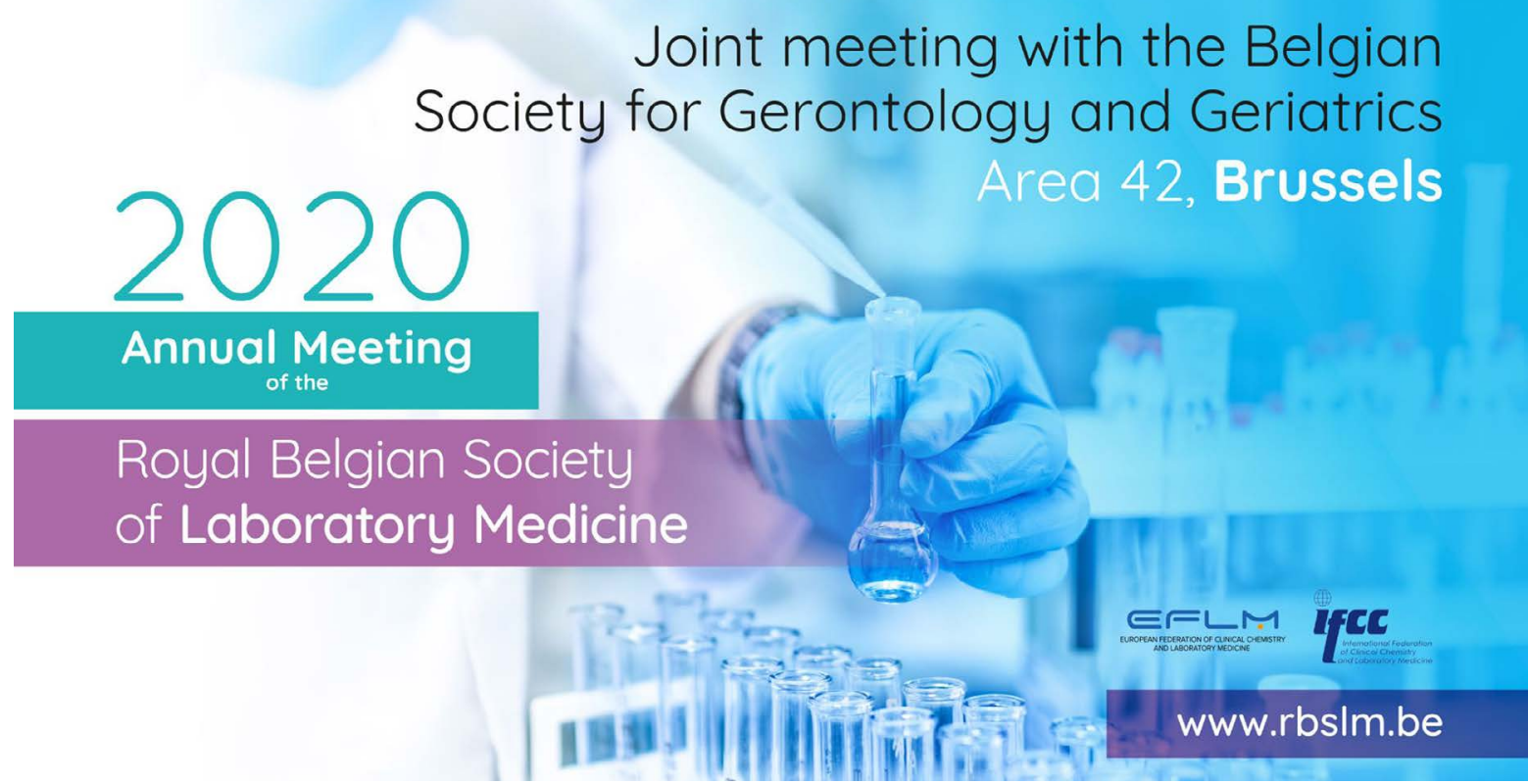

